\title{
State Support for Households with Children in COVID 19 Conditions: Comparative Analysis
}

\author{
Svetlana Kostina ${ }^{1, *}$, and Galina Bannykh ${ }^{2}$ \\ ${ }^{1}$ Ural Federal University, Institute of economics and management, School of public administration \\ and entrepreneurship, Mira 19, 620002 Yekaterinburg, Russia \\ ${ }^{2}$ Ural Federal University, Institute of economics and management, School of public administration \\ and entrepreneurship, Mira 19, 620002 Yekaterinburg, Russia
}

\begin{abstract}
.
Research background: The restrictions introduced by nation states to overcome the spread of the COVID19 pandemic had a negative impact on the situation of families with children due to lower incomes of the population, increased unemployment, and reduced opportunities for using social infrastructure (education, health, culture and sports). In order to overcome the consequences of the restrictions introduced during the COVID19, national states proposed various support measures not only for business, but also for the population, especially for families with children.

Purpose of the article: The purpose of the article is to conduct a comparative analysis of government support measures for families with children aimed at overcoming the socio-economic consequences of COVID 19, using the example of the Russian Federation and a number of countries in Europe and Asia.

Methods: as the main research methods are the analysis of documents, the analysis of statistical data.

Findings \& Value added: The analysis presents systematic data on measures of state support for families with children in various European and Asian countries. It is concluded that these measures are of a monetary nature (in the form of direct payments), and non-monetary nature (in the form of guarantees, benefits, material assistance of various kinds). At the same time, the question of the effectiveness of these measures to restore the socioeconomic situation of families with children during and after COVID19 remains controversial.
\end{abstract}

Keywords: households with children; COVID19; state support; socioeconomic status of households with children; monetary and non-monetary support measures.

JEL Classification: $H 53 ; 138 ; Z 13$

${ }^{*}$ Corresponding author s.n.kostina@urfu.ru 


\section{Introduction}

The world situation in 2020 is unique. Most states at the national level were forced to take restrictive measures for the social and economic activity of social actors. In turn, the imposed restrictive measures have caused an unprecedented economic crisis, as a result of which the socio-economic situation of billions of people around the world has significantly deteriorated. The International Labor Organization (ILO) estimates that approximately 25 million people around the world could lose their jobs due to the economic crisis caused by the COVID-19 pandemic [1]. A UN report says the poverty rate could rise by $420-580$ million people - the first increase in three decades - with 70-100 million at risk of falling back into extreme poverty [2].

In such conditions, families with children remain one of the most vulnerable categories. At the level of national states, the problem of supporting families with children in a pandemic was resolved ambiguously: not all countries supported this particular category of beneficiaries, support could be directed at children or parents, implemented in various forms (both monetary and non-monetary). Research problem faced by the authors: to systematize information on support measures for households with children for further analysis.

In this article, we will look at insurance and non-insurance programs to support families with children in various national states. Insurance measures include, for example, sick leave for parents. Non-insurance include tax breaks, lump-sum payments, cash payments to parents, childcare support, child nutrition, and other support measures.

The purpose of the article is to conduct a comparative analysis of government support measures for families with children aimed at overcoming the socio-economic consequences of COVID 19, using the example of the Russian Federation and a number of countries in Europe and Asia.

As a result of the analysis, the following issues were considered:

- measures of state support for employment aimed at parents with children;

- state support measures for families with children aimed at increasing consumer demand and reducing the risk of poverty.

\section{Methods}

As the main research methods are the analysis of documents, the analysis of statistical data.

Official documents of national states, UN documents [2-3], European Commission [4], analytical reports [5] were considered as documents for analysis.

In our analysis, we relied on a theoretical approach to the classification of support measures based on an analysis of support measures adopted nation-states in the context of the COVID-19 pandemic, which was proposed by researchers at the National Research University Higher School of Economics (Moscow, Russia) [6]

1. By directions: income support through subsidizing wages; (2) providing all categories of citizens with one-time subsidies to stimulate consumer demand; and (3) supporting vulnerable categories of the population, mainly the unemployed, families with children, and retirees.

2. By temporal characteristics: (by the time of the beginning of the action and by the duration of the action (temporary or permanent).

3. By type: social insurance measures and non-insurance programs.

4. 


\section{Results}

Support for families with children is one of the areas of modern state social policy of national states. Child support schemes are becoming increasingly important in connection with the increase in the number of divorces and the increase in the number of single families in different countries. [7] Analysis of modern research on government policies to support families with children has shown that, although this category is one of the most vulnerable to the risks of poverty, but does not always find an appropriate place in the social policy of supporting national states.

A significant amount of research in recent years has been devoted to the poverty of various categories of families with children. For example, a number of authors note high rates of poverty among single-parent families in Australia, Finland, Germany, and the UK, because existing measures simply reimburse costs, but do not affect poverty reduction [8]. K. Smith notes that after the global financial crisis, nation-states began to revise their policies in relation to supporting families and children, focusing on ensuring the early years, as it offers the most significant potential for profit, especially in relation to "disadvantaged" children [9]

Hard economic policies have influenced government support systems in other European countries. Lindberg, M., Nygård, M. and Nyqvist, F. note that in Finland in recent years sluggish growth, high unemployment and periodic austerity measures have gradually eroded the economic security of families, especially among single-parent families and large families, and this has put families into growing tensions and increased the risks of poverty, inequality and other forms of disadvantage [10].

Kostina, Bannykh, Zaitseva, considering the state policy of the Russian Federation in relation to families with children, note that it includes various areas - related to supporting the employment of parents (mainly mothers), measures to ensure the health and education of children, as well as measures aimed at reducing poverty families with children and ensuring a decent standard of living [11] The last group of measures has a rather complex configuration due to such parameters as the presence of federal and regional measures, more than two dozen categories of their recipients, a variety of types of measures themselves (one-time and monthly; benefits, payments, compensation, granting of rights, etc.), various subjects of the implementation of measures.

Experts are confident that the consequences of the COVID-19 pandemic will primarily strongly affect vulnerable and disadvantaged groups, such as, for example, families with children or low-income households [12].

Considerable attention of researchers in 2020 was focused on the problem of domestic violence in households during a pandemic [13, 14], the aggravation of problems with unpaid care work for women as a direct consequence of the pandemic [15], and issues of the well-being of women and children [16].

J. Han, B.D. Meyer, J.X. Sullivan found the positive impact of economic measures taken by nation-states for families with children at the beginning of the pandemic [17]. Thus, in their opinion, the public policy effectively counteracted the impact of the pandemic on income, which led to a reduction in poverty and an increase in low-income percentiles in a number of demographic groups and geographic regions. Authors from France suggest that developing countries use a wider range of social protection and support measures during a pandemic than developed countries [18].

It should also be noted that the bulk of measures to support families with children are temporary in nature, the periods (beginning and duration) of their application differ in national states. Although most of the measures countries began to introduce at the beginning of the pandemic period (March-April 2020), we see that some measures were 
proposed later. A number of measures are currently being discontinued, while others continue to be implemented and/or are being extended for a later period.

A significant number of European countries have made efforts to support employment and labor rights of various categories of citizens. These measures only partially directly concerned families with children, since most of the support was directed to such categories as the employed, self-employed, small or family businesses, and the unemployed. Of course, these measures also affect the situation of families with children. It is assumed that at least one parent has earned income.

However, a number of countries have adopted specific employment measures aimed at parents with children. First, this is the provision of special paid leave for working parents to care for children who do not attend child care facilities during the pandemic [11].

In Lithuania, the measures introduced concerned the provision of sickness benefits for caregivers, elderly people, and people with disabilities who are not allowed to attend kindergarten centers, kindergartens, schools, etc. (65.94\% of their gross salary). In Cyprus, for the period March 16-12, 2020, special leave was introduced for parents working in the private and public sector at the time when schools, private or public, kindergartens, or other educational institutions suspend their work (actual payments for the period amounted to 17,81 million euros). Luxembourg introduced simplified procedures for applying for special family leave due to school closures, including a one-time special advance payment to companies to recover costs (estimated impact of 222 million euros). Since May 25, the period of special leave for family reasons has been extended for parents of children who were forced to stay at home for organizational reasons.

In Malta, families with children in which both parents work and cannot work remotely and therefore require parental leave to look after their children should be eligible for two months additional leave and receive an allowance of 800 euros per month. In Poland, the package of measures for the employed from 1 April 2020 also provided for working parents who need to stay at home to take care of their children due to the closure of childcare facilities, the right to parental leave to care for his/her child under the age of 8, and the right for a special additional allowance for leaving the funds of state insurance protection.

In Italy, a temporary measure was introduced starting March 5 for workers with children under 12 years of age in the form of leave to use for the purpose of caring for children who do not attend educational institutions, up to 15 days, paid at $50 \%$ of earnings and funded by the state.

Portugal introduced financial support for workers who need to stay at home to care for children under 12 who cannot go to school, amounting to $2 / 3$ of gross wages (equal share by the employer and social security); special financial support for the self-employed, costs $1 / 3$ of the median compensation.

In Slovenia, workers who were forced to stay at home and look after their children due to the fact that kindergartens and schools were closed or due to the inability to come to work due to public transport stops or the closure of national borders were also entitled to 80 $\%$ compensation of wages and compensation of all social security contributions paid by the state (estimated budgetary implication: 400 million euros). In Slovakia, both parents in quarantine (sickness benefit) and people caring for a family member (care benefit) will receive $55 \%$ of their salary during the pandemic. Greece has introduced special leave, partly funded $(25 \%)$ by the government, to help parents of children under 15 work in the private and public sector following general school closures. The budget is estimated to be about 20 million US dollars.

In Finland, parents who are absent from work due to coronavirus, as well as parents who have lost income from employment due to the fact that their children do not attend preschool or school, the government provides an allowance as part of an additional package of measures adopted in April at the level of the minimum parental allowance - 28.94 euros 
per working day (723.50 euros per month). The payment of benefits covers the period from the introduction of the state of emergency - from March 16 [1].

Also, nation-states have taken a number of other measures for working parents. For example, in France, the waiting period for additional compensation paid by the employer for childcare to parents and the increase in replacement income to $90 \%$ of net wages were canceled. Spain introduced flexible working conditions, encouraging teleworking, and adjusting working hours - reducing working hours for workers caring for children, the elderly, or dependents.

In Italy, measures to support work from home, including the right for those workers who have at least one dependent child under the age of 14 to work from home, provided this is compatible with the performance of the work, have been introduced.

Latvia has also introduced temporary support measures for busy parents. An allowance for non-working employees (including self-employed) has been established in the amount of $75 \%$ of the previous salary (no more than 700 euros per month). Employees and selfemployed persons are eligible for a downtime benefit of 180 euros per month and a supplement of 50 euros per month for a dependent child. This assistance will be provided until June 30, 2020. Paid out 42.8 million euros. An additional 1.3 million euros has been paid for downtime allowance and dependent child support.

South Korea also has measures to provide parental leave (up to ten days a year) for workers in dire need of childcare while preschool and school facilities are closed. Provides a temporary subsidy of 50,000 won per worker (40 US dollars) who receives parental leave (up to 500,000 won per couple; 408 US dollars ) to provide practical support for those in urgent need of childcare.

As we can see, most of the measures are temporary and are effective during a pandemic.

The second group of efforts to support families with children that have been undertaken by nation-states can be attributed to supporting consumer demand and helping vulnerable groups of the population. It is quite diverse in nature and is represented by both the introduction of new temporary measures and an increase or change in the procedure for obtaining existing support measures. Here we also see that families with children are rarely the target support group. Basically, the coverage of these measures extends to a fairly wide range of recipients (or to all citizens). This also applies to tax and credit preferences. Of course, they also affect family members with children. However, we will try to focus on specific measures for families with children.

Firstly, these are temporary measures introduced for the period of the pandemic. These include, first of all, various lump-sum payments and benefits.

In Italy, the government approved a lump-sum payment of 120 euros for children or 200 euros for disabled children from large and low-income families. There is also an allowance for paying for babysitting (baby sitter) services for children under 12 years old in the form of a voucher - from 600 to 1000 euros [1].

Also, temporary measures concern the provision of nutrition for children. For example, the UK launched a national voucher scheme effective March 31, 2020 to ensure that 1.3 million school-age children previously eligible for free school meals will be eligible for food during school closures caused by COVID-19. Under this scheme, each (eligible) school-age child will receive a voucher of 15 pounds per week (equivalent to 3 pounds per day). The cost of vouchers exceeds the cost of free school meals as the government recognizes the increased costs for parents, given that they will not buy food in bulk and therefore incur higher costs.

Spain is providing an additional 25 million euros loans to cover food costs to ensure basic access to food for vulnerable children affected by school disruptions.

In Japan, measures taken at the regional level include the provision of free meals by the Osaka City government to students in public elementary and secondary schools. 
Secondly, these are lump-sum payments for children or families with children. Let us give examples of the application of these measures in national states. In Latvia, a lump-sum payment of 150 euros was paid to parents caring for children. In Poland, a one-time payment to families of 360 euros per child was provided, which is payable in September 2020. In Slovenia, a one-time crisis bonus was paid including to families with three (100 euros) or more children (200 euros), families with less than three low-income children (30 euros per child).

In Finland, due to the incidence of coronavirus, the government has introduced a special sickness benefit due to infectious disease, which is paid to sick people who must be isolated (or whose children under 16 years old must be isolated) by the order of the doctor responsible for controlling the spread of infectious diseases in a municipal or hospital district. Documents for such an allowance are submitted online.

Japan has provided for a payment of 300,000 yen per household to support the expenditures of needy households, especially households with children and low incomes.

In South Korea, the government has also decided to offer 9.1 trillion won in emergency aid to households in the bottom 70 percent income segment. Benefits vary by household member: one-person households 0.4 million won, two-person households 0.6 million won, three-person households 0.8 million won, and four-person households 1.0 million won (816 US dollars).

In Kazakhstan, a social benefit in the amount of 42.5 thousand tenges (100 US dollars) is received by persons who would have paid the CAP once (with the exception of women with children under 1 year old who are already receiving benefits). According to government estimates, the number of recipients of this payment will be 3 million. A number of socially vulnerable categories, including large families and children with disabilities, will receive free food and household kits, in order to ensure the efficiency and safety of citizens - by transferring funds to the accounts of individuals.

Armenia provided one-time payments in the amount of 26.5 thousand Armenian drams to all families with children under 18 years old, and both parents were not registered employees (provided that the children and at least one of the parents live in the Republic of Armenia are not beneficiaries family allowance, parents' income for the period January 1 March 1, 2020 did not exceed 500 thousand drams). The recipient of this compensation can be a family in which the parent is on parental leave to care for a child under 3 years old. Financial assistance is provided to families with children under 14, whose parents were fired during the state of emergency. One-time financial assistance is provided to pregnant women who do not have a job, whose husbands were dismissed due to restrictions in the state of emergency or died during the state of emergency, in the amount of 100 thousand drams [1].

The government of the Russian Federation has introduced a number of payments aimed specifically at supporting families with children of different ages. These include, firstly, a lump-sum payment for each child between the ages of 3 and 16, regardless of the family's income in the amount of 10,000 rubles. The amount of this payment is quite high, it is close to the minimum subsistence level for a child, and, according to the estimates of the Government of the Russian Federation, this benefit will be received for more than 19.7 million children. Secondly, these are monthly payments for a period of three months (paid in April, May, June 2020). The payment for each child under 3 years of age in the amount of 5,000 rubles per month. This payment will range from $45 \%$ to $50 \%$ of the regional subsistence minimum for a child and approximately 5 million children will be able to receive it. It is also a monthly payment for each child under 18 years of age in the amount of 3,000 rubles per month, whose parents are registered with the employment service as unemployed and receive unemployment benefits. This payment will be from $25 \%$ to $30 \%$ of the regional minimum subsistence level of the child. In general, these benefits will add to 
the income of citizens of about 288 billion rubles. These investments amount to $0.5 \%$ of the population's monetary income in 2019. In addition to the support measures provided by the Federal government, certain regions of the Russian Federation have also introduced additional measures to support families with children. For example, the support for those families with children who are not eligible for federal payments. Thus, the Republic of Crimea makes lump-sum payments to low-income families with children aged 16 to 18 in the same amount as at the federal level - 10 thousand rubles. The Perm Territory pays 10.7 thousand rubles at a time to low-income families with children aged 1.5 to 3 years, who are not provided with either federal or regional monthly support measures. In the Leningrad Region, in April, all large families, low-income families and families with disabled children aged 1 to 18 years received one-time payments in the amount of 3 thousand rubles, and in the Sverdlovsk region - 5 thousand rubles; in the Krasnodar Territory, large families are paid 2 thousand rubles for each child. In the Udmurt Republic, support is provided for lowincome non-working pregnant women.

The second direction is to increase the size or change the procedure for obtaining existing support measures for families with children.

In Germany, low-income families receive additional support through increased child support benefits and easier access to minimum social support schemes. To receive child support for self-employed and small business owners, it is enough to prove income for the last month, and not for the previous 6 months, as it was before.

France has extended the rights to access minimum social benefits for the period of maintenance: income from active solidarity (RSA), complementary health care (CSS), benefits for the disabled and children.

In Latvia, the allowance paid to the guardian for the maintenance of the child during the pandemic was increased by $50 \%$ (the cost is estimated at 0.5 million euros), the childcare allowance for parents caring for children from 1.5 to 2 years old was increased from 42, 69 euros to 171 euros (cost until June 30, 2020 - 2.8 million euros.) Local social assistance is compensated by the state $-50 \%$ of the crisis allowance is paid, but not more than 40 euros per person per month and a supplement of 50 euros for a dependent child.

The Government of Malta has increased the rental subsidy for those families who already live in subsidized housing and where one family member has been laid off. Sweden has temporarily increased the supplementary housing allowance for families with children who are already receiving housing allowance from 1 July until the end of 2020, up to a maximum of SEK 1,325 per month (finance cost: SEK 560 million).

In Kazakhstan, pensions and state benefits, including targeted social assistance, were indexed by $10 \%$ in annual terms (for a total amount of 315.6 billion tenges).

In Armenia, every family receiving family or social benefits as of April 2020 is provided with additional support in the amount of $50 \%$ of the amount of the benefit, of which $70 \%$ is provided to the family in cash along with the April benefit, and $30 \%$ is transferred as a subscription fee for electricity. It is expected that the recipients of this measure will be about 85 thousand families (as of April 2020), and the total cost of its implementation will amount to about 1.2 billion drams.

In the Russian Federation, during the pandemic, measures were introduced to support low-income families. These include a monthly payment for a child aged 3 to 7 years inclusive (as of January 1, 2020) in the amount of 0.5 of the child's regional subsistence minimum. This payment is assigned to families whose average per capita income per month does not exceed the subsistence level established in the subject of the Russian Federation. It also provides for an increase in the size of the monthly allowance for caring for the first child until he reaches the age of one and a half years for non-working citizens. The minimum amount of the allowance received by non-working women, including students and mothers fired during parental leave or during maternity leave (due to the liquidation of 
the organization), has been doubled (to 6,752 rubles). In 2020, these measures will add about 120 billion rubles to the income of citizens, which is $0.2 \%$ of the income of the population in 2019 .

The regions of the Russian Federation also took additional measures in this direction. For example, this is an increase in payments to children whose parents have lost their jobs. So, in the Lipetsk region, families with children in which one (in an incomplete family) parent or both parents (in a complete family) in connection with the introduction of antiepidemic measures are on forced leave without support receive 12,130 rubles per family; in the Krasnodar Territory, if an unemployed person receives unemployment benefits in the minimum amount, then 3 thousand rubles are paid for each child.

One of the most presented areas of support measures in nation-states is various tax preferences. For example, Portugal has introduced a state moratorium (covering the principal amount, interest, and other fees) on loans to individuals for the most affected categories of the population, including the unemployed, laid-off workers, providing assistance to children or grandchildren who are in preventive isolation or who are sick due to COVID-19. In Finland, debt collection can be suspended for up to 6 months if a person is experiencing economic difficulties due to the crisis caused by the spread of the coronavirus (except alimony). In Kazakhstan, in order to support the population in a crisis, a ban on the imposition of fines and penalties on overdue payments for the period of the emergency has been introduced. The population affected by the crisis has been given the right to suspend payments of principal and interest on all loans.

Nation states have also introduced other measures to support children and families with children. For example, these are tourist vouchers that can be spent at tourist sites. For example, in Slovenia, their size was 200 euros for people over 18 years old and 50 euros for children (until the end of the year). In Poland, a tourist voucher is provided in the amount of PLN 500 (approx. 110 euros) per child, which must be redeemed by March 2021. An estimated 6 million children can benefit from this.

\section{Discussions}

The amounts allocated to support families were generally commensurate with the budgets and population of individual states. So, the Council of the European Union agreed on the allocation of 37 billion euros, in the United States the amount amounted to 40 billion US dollars, in the Russian Federation more than 2 trillion rubles (13 billion US dollars) were allocated for support. The analysis showed that more often countries rely on existing social programs, temporarily modifying them for the period of the greatest spread of coronavirus and quarantine measures, less often new social programs are proposed. Countries with pre-crisis lower levels of poverty and unemployment, with more universal (in terms of coverage) social support systems during the crisis, offer fewer new noninsurance support measures, since the existing instruments are sufficient. On the contrary, countries in which the problems of unemployment and poverty were acute even before the crisis, with less developed social support systems, during the crisis are forced to take more measures supporting various categories of the population.

Researchers note that Western European countries have mainly followed the path of subsidizing wages and one-off payments to stimulate consumer demand; The US has focused on supporting the unemployed and other vulnerable groups; Russia has chosen the path of primarily supporting families with children. 


\section{References}

1. UN working to fight COVID-19 and achieve Global Goals (2020, march). Official website of United Nations organization. Retrieved from: URL: https://www.un.org/ru/coronavirus/un-working-fight-covid-19-and-achieve-global-goals

2. United Nations Comprehensive Response to COVID-19 Saving Lives, Protecting Societies, Recovering Better (2020, august) Official website of United Nations organization. Retrieved from: URL: https://www.un.org/sites/un2.un.org/files/uncomprehensive-response-to-covid-19.pdf.

3. A UN framework for the immediate socio-economic response to COVID-19 (2020, april). Official website of United Nations organization. Retrieved from: URL: https://www.un.org/sites/un2.un.org/files/un_framework_report_on_covid-19.pdf

4. Policy measures taken against the spread and impact of the coronavirus - 20 (2020, august). Official website of European commission. Retrieved from: URL: https://ec.europa.eu/info/sites/info/files/coronovirus_policy_measures_20_august.pdf

5. Review of international practice of supporting the economy and population in the fight against the coronavirus pandemic in Armenia, Great Britain, Germany, Denmark, Spain, Italy, Kazakhstan, China, the Netherlands, USA, Finland, France, Sweden, South Korea, Japan (2020)/General edition O.V. Sinyavskaya. Institute for Social Policy, National Research University Higher School of Economics. Retrieved from: URL: https://isp.hse.ru/data/2020/04/29/1544579194/COVID-

19_stimulus\%20packages_countries260420.pdf

6. Pishnyak A. I., Korchagina I. I., Gorina E. A., Ter-Akopov S. A. (2020). Supporting families with children amid the COVID-19 pandemic. HSE Analytical Bulletin on the Economic and Social Consequences of Coronavirus in Russia and in the World, 7.

7. Hakovirta, M., Jokela, M. (2018) Contribution of child maintenance to lone mothers' income in five countries. Journal of European Social Policy, 29(2), 257-272.

8. DiPrete, T. A, Eirich, G. M. (2006). Cumulative advantage as a mechanism for inequality: A review of theoretical and empirical developments. Annual Review of Sociology, 32(1), 271-9.

9. Smith, K. (2019). Better with less: (Re)governmentalizing the government of childhood. International Journal of Sociology and Social Policy, 39(1/2), 68-83.

10. Lindberg, M., Nygård, M., Nyqvist, F. (2018). Risks, coping strategies and family wellbeing: evidence from Finland. International Journal of Sociology and Social Policy, 38(11/12), 1116-1132.

11. Kostina, S., Bannykh, G., Zaitseva, E. (2020). The influence of state policy on households with children on the reproduction of human capital in the Russian Federation. Proceedings of the 14th International Days of Statistics and Economics, Prague, Czech Republic.

12. Fallon B., Lefebvre R., Collin-Vezina D., Houston E., Joh-Carnella N., Malti T. (2020). Screening for economic hardship for child welfare-involved families during the COVID-19 Pandemic: A rapid partnership response, Child Abuse \& Neglect, 104706.

13. Usher, K., Bhullar, N., Durkin, J., Gyamfi, N., Jackson, D. (2020). Family violence and COVID-19: Increased vulnerability and reduced options for support. International Journal of Mental Health Nurs, 29, 549-552.

14. Gilbertson W.N., Hiles H.A., Pop P. (2020) Data-informed recommendations for services providers working with vulnerable children and families during the COVID-19 $\begin{array}{llll}\text { pandemic. } \quad \text { Abuse } \quad \text { \& } & \text { Neglect, }\end{array}$ 
https://www.sciencedirect.com/science/article/pii/S0145213420302970 (accessed 09.09.2020).

15. Elran-Barak R., Mozeikov M. (2020) One month into the reinforcement of social distancing due to the COVID-19 outbreak: Subjective health, health behaviors, and loneliness among people with chronic medical conditions. International Journal of Environmental Research and Public Health, 17(15), 5403.

16. Patrick S., Henkhaus L., Zickafoose J., Lovell K., Halvorson A., Loch S., Letterie M., Davis M. (2020). Well-being of parents and children during the COVID-19 pandemic: A national survey pediatrics, https://pediatrics.aappublications.org/content/early/2020/08/28/peds.2020-016824 (accessed 09.09.2020).

17. Han J., Meyer D.B., Sullivan J. (2020). Income and poverty in the COVID-19 pandemic brookings paper on economic activity, https://www.brookings.edu/wpcontent/uploads/2020/06/Han-et-al-conference-draft.pdf (accessed 09.09.2020).

18. Gerard F., Imbert C., Orkin K. (2020). Social protection response to the COVID-19 crisis: options for developing countries. Oxford Review of Economic Policy, https://econfip.org/policy-brief/social-protection-response-to-the-covid-19-crisisoptions-for-developing-countries/ (accessed 09.09.2020). 